\title{
Avaliação de Custos e Desperdícios na linha de Produção de Tortas Promocionais em uma Indústria de Alimentos
}

Carla Andréa Mendonça de Albuquerque
Graduação em Engenharia de Alimentos pela Universidade
Federal da Paraíba - UFPB
Campus I. Lot. Cidade Universitária. João Pessoa/PB. CEP: $85.015-430$ E-mail: carlamendonca-@hotmail.com

Maria Silene Alexandre Leite Pós-Doutorado em Administração pela Universidade Federal de Pernambuco - UFPE Professora da Universidade Federal da Paraíba - UFPB Campus I. Lot. Cidade Universitária. João Pessoa/PB. CEP: 85.015-430 E-mail: mariasileneleite@hotmail.com

Stela de Lourdes Ribeiro de Mendonça Doutorado em Engenharia Mecânica pela Universidade Federal da Paraíba - UFPB Professora da Universidade Federal da Paraíba - UFPB Campus I. Lot. Cidade Universitária. João Pessoa/PB. CEP: 85.015-430 E-mail: steladelourdes@gmail.com

\section{RESUMO}

O crescimento da indústria de panificação e confeitaria foi de $3,2 \%$ no ano de 2018 , sendo considerada um dos pilares da economia. Apesar da significativa contribuição, este setor também apresentou problemas relacionados com a eficiência produtiva e com o aumento do consumo de matéria-prima e energia, gerando desperdícios. Considera-se a importância da identificação dos custos e desperdícios para a produtividade e auxílio na tomada de decisões gerenciais. Este trabalho também possibilitou entender o comportamento dos custos e desperdícios na linha de tortas promocionais de uma indústria de pequeno porte. A respeito dos objetivos específicos, pode-se citar: analisar o sistema de produção utilizado pela empresa; identificar custos e despesas; identificar os desperdícios e propor soluções viáveis para a redução desses. Para alcançar os objetivos propostos utilizou-se o método do estudo de caso exploratório, com abordagem qualitativa. $O$ resultado da pesquisa revelou que os custos de produção mais significativos são os de matéria-prima, mão de obra e energia, os quais estão diretamente relacionados a uma grande quantidade de atividades que não agregam valor, que representam $54,7 \%$. Observou-se oportunidades de melhorias no processo por meio da implantação do sistema de planejamento e controle de produção (PCP) e da padronização do processo. Para tanto, faz-se necessário o comprometimento da empresa na realização das mudanças propostas para a redução dos custos gerados pelos desperdícios.

Palavras-Chave: Custos. Custo Gerencial. Desperdícios. Confeitaria. 
Avaliação de Custos e Desperdícios na linha de Produção de Tortas Promocionais em uma Indústria de Alimentos

Carla Andréa Mendonça de Albuquerque, Maria Silene Alexandre Leite, Stela de Lourdes Ribeiro de Mendonça

\section{Evaluation of Costs and Waste in the Production Line of Promotional Pies in a} Food Industry

\section{ABSTRACT}

The growth of the bakery and confectionery industry was $3.2 \%$ in 2018 , being considered one of the pillars of the economy. Despite the significant contribution this sector also presented problems related to production efficiency, increased consumption of raw materials and energy, generating waste. Considering the importance of identifying costs and waste for productivity and helping with management decision making, this work has made it possible to understand the behavior of costs and waste in the pie line of a small industry. As specific objectives, we can mention production of promotional pies, as specific objectives: to analyze the production system used by the company; identify costs and expenses; identify waste and propose viable solutions to reduce waste. To achieve the proposed objectives, the exploratory case stusy method was used, with a qualitative approach. The survey result revealed that the most significant production costs are those of raw materials, labor and energy which are directly related to a large amount of non-value added activities, which represent $54.7 \%$. Opportunities for process improvement were observed through the implementation of the production planning and control system and the standardization of the process. Therefore, the company's commitment to make the proposed changes is necessary to reduce the costs generated by waste.

Keywords: Costs. Managerial Cost. Waste. Confectionery

\section{Evaluación de los costos y desperdicios em la línea de producción tarta promocionales em uma indústria alimentícias}

\section{ABSTRACT}

El crecimiento de la industria de panadería y confitería fue del 3,2\% en 2018, siendo considerado uno de los pilares de la economía. A pesar de un aporte importante, este sector también presentó problemas relacionados con la eficiencia productiva y el aumento del consumo de materias primas y energía, la generación de desperdicio. Se considera la importancia de identificar costos y desperdicios para la productividad y la toma de decisiones administrativas. Este trabajo también permite comprender el comportamiento de los costos y desperdicios en la línea de tarta promocionales de una pequeña indústria. En cuanto a los objetivos específicos, se menciona: analizar el sistema productivo que utiliza la empresa; identificar costos y gastos; identificar desperdícios y proponer soluciones viables para reducirlos. Para lograr los objetivos propuestos se utilizou el método de estudio de caso exploratorio, con un enfoque 
Avaliação de Custos e Desperdícios na linha de Produção de Tortas Promocionais em uma Indústria de Alimentos

Carla Andréa Mendonça de Albuquerque, Maria Silene Alexandre Leite, Stela de Lourdes Ribeiro de Mendonça

cualitativo. El resultado de la investigación reveló que los costos más significativos de producción son materias primas, mano de obra y energía, que están directamente relacionados con una amplia gama de actividades que no agregan valor, representan $54,7 \%$. Se observaron oportunidades de mejora en el proceso mediante la implementación del sistema de planificación y control de producción (PCP) y la estandarización del proceso. Pero, es necesario comprometer a la empresa a realizar los cambios propuestos, para reducir los costes generados por los desperdicios.

Palabras clave: Costos. Costo de gestión. desperdicio. Confitería.

\section{INTRODUÇÃO}

No Brasil, a indústria de alimentos gerou mais de 13 mil postos de trabalho com faturamento de $2,8 \%$, sendo considerado como um dos pilares da economia. Nesse cenário estão inseridas indústrias de transformação, dentre elas a de panificação e confeitaria. Quando comparado ao ano de 2017, o crescimento da indústria de panificação e confeitaria foi de $3,2 \%$ que equivale à $R \$ 90,3$ bilhões. Tal percentual é inferior aos anos anteriores, um dos motivos para isso é o aumento dos custos operacionais e a redução do ritmo de investimento das empresas. Esse resultado reforça a necessidade de manter a oferta de produtos e alto padrão de qualidade para se tornar mais competitiva e conciliar o aumento da oferta de produtos e serviços com a redução de custos (Abip, 2018).

Nesse sentido, Fernandes (2014) reforça que apesar da significativa contribuição do setor de panificação e confeitaria, esse segmento também apresentou problemas relacionados com a eficiência produtiva e está diretamente ligada ao aumento de consumo de matéria-prima e energia, resultando na geração de resíduos e desperdícios. A fórmula do lucro unitário se apresenta com o custo fixado subtraindo o lucro necessário para manter o preço de venda estável (Shingo, 1996). Sendo assim, mantendo o preço constante, os parâmetros custo e lucro são inversamente proporcionais. Dessa forma, para que as indústrias de panificação e confeitaria consigam aumentar o lucro, é indispensável que haja a redução dos custos. 
Avaliação de Custos e Desperdícios na linha de Produção de Tortas Promocionais em uma Indústria de Alimentos

Carla Andréa Mendonça de Albuquerque, Maria Silene Alexandre Leite, Stela de Lourdes Ribeiro de Mendonça

A diminuição dos custos nas empresas é um objetivo perseguido, porém para que se concretize é necessário identificar os custos, para que seja possível verificar oportunidades de melhoria no processo que resultem na identificação de atividades que não agregam valor ao produto. Posto que, em um processo produtivo, tudo que gera custo e não adiciona valor é considerado como desperdício, para tanto, deve ser eliminado (Albertin \& Guertzenstein, 2018). A redução de desperdícios é bastante empregada na filosofia Lean Manufacturing, na qual é empregada neste trabalho para apuração dos desperdícios gerados na produção de tortas promocionais. Desse modo, a redução de custos se apresenta como uma contribuição para a manutenção da eficiência nas empresas, em especial nas pequenas e médias que sofrem com carências de ferramentas e técnicas que possam auxiliar no alcance deste objetivo. Importante salientar que esse problema afeta negativamente seu desempenho, gerando a necessidade de trabalhos que auxiliem na implantação de ferramentas de gerência de custos.

Geitenes (2013) afirma que o processo de eliminação de atividades desnecessárias, com objetivo de produzir apenas o essencial, é conhecido como produção enxuta. A partir desse processo é possível avaliar a produção, identificar oportunidades de melhoria e principalmente reduzir custos.

Este estudo foi realizado em uma indústria do ramo da confeitaria que iniciou sua trajetória em 1991. Essa foi selecionada devido à preocupação da gerência com os elevados gastos da linha promocional de tortas que geram uma quantidade de desperdícios significativos e apesar dessa constatação não há contabilização dos gastos, o que dificulta a variação dos preços pela gestora em datas comemorativas. Esse dilema entre a falta de mensuração dos gastos e a insegurança da gestora para variar os preços das tortas em períodos de promoção, constituem o problema de pesquisa deste trabalho. Diante desse cenário, este trabalho levantou o custo gerencial e identificou os desperdícios no processo produtivo da linha de produção de tortas promocionais. Os resultados obtidos demonstraram que os custos de produção mais significativos são os de matéria-prima, mão de obra e energia, os quais estão 
Avaliação de Custos e Desperdícios na linha de Produção de Tortas Promocionais em uma Indústria de Alimentos

Carla Andréa Mendonça de Albuquerque, Maria Silene Alexandre Leite, Stela de Lourdes Ribeiro de Mendonça

diretamente relacionados a uma grande quantidade de atividades que não agregam valor, representando $54,7 \%$, os quais são gerados pelo processo desperdício ao longo do processo de produção.

\section{REFERENCIALTEÓRICO}

Nesta seção, apresenta-se a fundamentação teórica que orientou a pesquisa, destacando o custo gerencial, suas terminologias e conceitos. Ainda, uma breve explicação da importância e dos tipos de sistema de produção, o sistema de produção enxuta e a definição dos sete tipos de desperdícios e, por fim, a apresentação das ferramentas enxutas que foram utilizadas.

\subsection{Custo Gerencial}

Para realizar o controle de custos em uma indústria é necessário ter o domínio sobre gastos com insumos que são utilizados para o processo de transformação da matéria-prima em produto acabado. Esses são conhecidos como custos de transformação, os quais são de grande importância para a gestão da produção (Lacerda, Walter \& Schultz, 2011).

De acordo com Leone (2000), a contabilidade de custos é um processo que tem como finalidade auxiliar atividades gerenciais, como:

- Determinação do Lucro e Avaliação do Patrimônio por meio da determinação da acumulação dos custos e de critérios de rateio;

- Controle das Operações e Planejamento por meio do emprego de custos padrão e custos estimados;

- Tomada de Decisões gerenciais pode ser facilitada a partir do uso dos custos fixos e variáveis.

Classificado como o valor de bens e serviços utilizados com o funcionamento da empresa, o custo gerencial (CG) pode ser calculado a partir da soma dos custos diretos, indiretos e despesas. Cujo a fórmula é apresentada na Equação 1. 
Avaliação de Custos e Desperdícios na linha de Produção de Tortas Promocionais em uma Indústria de Alimentos

Carla Andréa Mendonça de Albuquerque, Maria Silene Alexandre Leite, Stela de Lourdes Ribeiro de Mendonça

$$
C G=M P+M O D+C I F+\text { Despesas }
$$

Onde:

$\mathrm{MP}=$ Matéria-prima

$M O D=$ Mão de obra direta

$\mathrm{CIF}=$ Custos indiretos de fabricação

De acordo com Bornia (2010), os custos de mão de obra direta são aqueles diretamente ligados aos operadores que trabalham diretamente na confecção do produto, assim como, a matéria-prima são os materiais consumidos durante o processo de produção, dessa forma, esses custos são chamados de Custos de Fabricação (CF) e por esse motivo a Equação 1 pode ser escrita também como (Equação 2):

$$
C G=C F+\text { Despesas }
$$

Por meio desses itens é possível encontrar o custo unitário, que pode ser calculado através da divisão do custo gerencial pela quantidade produzida. Além dos benefícios já citados, o conhecimento do custo de produção auxilia na identificação de melhorias através da identificação e eliminação de desperdícios que aumentam os custos de produção e reduzem a lucratividade das empresas (Oliveira, 2016).

A partir do estudo de identificação dos custos e da formação do preço de venda dos produtos de uma indústria de panificação localizada no oeste do Estado de Santa Catarina, Magro, Manfroi, Bortoli e Theisen (2014) afirma que, a contabilidade de custos é primordial para o gerenciamento do processo produtivos e formação do preço de venda. Posto que, nesse caso, teve uma contribuição significativa para a identificação da rentabilidade e lucratividade dos produtos.

Através do estudo de aplicação do método de custeio variável em uma indústria do setor de panificação e confeitaria do Município de Nova Veneza-SC. Para Demeneck (2014), uma aplicação correta dos métodos de custeio e outros métodos da área de custos há uma contribuição direta na tomada de decisões nas empresas. 
Avaliação de Custos e Desperdícios na linha de Produção de Tortas Promocionais em uma Indústria de Alimentos

Carla Andréa Mendonça de Albuquerque, Maria Silene Alexandre Leite, Stela de Lourdes Ribeiro de Mendonça

O custo gerencial é uma abordagem relevante para a gestão das empresas, ele possibilita um conhecimento profundo sobre o negócio e promove vantagens em relação à concorrência e às políticas de formação de preços.

\subsection{Sistema de Produção Enxuta}

O sistema de produção enxuta também conhecido como Lean Manufacturing é uma filosofia baseada nas práticas utilizadas pelo Sistema Toyota e nos resultados alcançados através dela. O Lean Manufacturing, segundo Ohno (1997) não possui metas específicas nem um passo a passo a ser seguido, porém deve estar em constante renovação e em estado de melhoria contínua. Sendo que todo o desperdício deve ser tratado de forma que seja reduzido e posteriormente eliminado. A eliminação/diminuição de desperdícios é um dos principais passos para redução de custos operacionais.

\subsubsection{Os sete desperdícios}

Todo esforço econômico que não agrega valor ao produto, assim como ineficiências no processo são considerados desperdícios. A mensuração desses é de grande importância para a empresa, posto que, influencia diretamente no custo de produção (Bornia, 2010). Ohno (1997) destaca que os desperdícios devem ser classificados em sete tipos: superprodução, excesso de estoque, produtos defeituosos, processamento, espera, excesso de movimentação e transporte. Esses são apresentados no Figura 1. 
Avaliação de Custos e Desperdícios na linha de Produção de Tortas Promocionais em uma Indústria de Alimentos

Carla Andréa Mendonça de Albuquerque, Maria Silene Alexandre Leite, Stela de Lourdes Ribeiro de Mendonça

\begin{tabular}{|c|c|c|}
\hline DESPERDÍCIO & DEFINIÇÃO & AUTOR(ES) \\
\hline Superprodução & $\begin{array}{l}\text { Desperdício ocasionado pelo excesso de } \\
\text { produção ou quando os itens são produzidos } \\
\text { antes do programado }\end{array}$ & $\begin{array}{l}\text { Liker e Meier } \\
(2007) \text {; Shingo } \\
(1996)\end{array}$ \\
\hline Defeito & $\begin{array}{l}\text { É definido como o não atendimento a um } \\
\text { requisito relacionado a um uso pretendido e/ ou } \\
\text { especificado }\end{array}$ & $\begin{array}{l}\text { Linker (2005); } \\
\text { ABNT (2000) }\end{array}$ \\
\hline Processamento & $\begin{array}{l}\text { É o excesso de atividades que não são } \\
\text { necessárias para que o produto obtenha suas } \\
\text { características da qualidade }\end{array}$ & Antunes (2008) \\
\hline Espera & $\begin{array}{l}\text { Está relacionado a tempos ociosos durante o } \\
\text { processo de produção }\end{array}$ & $\begin{array}{l}\text { Chiavenato } \\
\text { (1993) }\end{array}$ \\
\hline Movimentação & $\begin{array}{l}\text { Este desperdício está ligado ao excesso de } \\
\text { deslocamento dos funcionários para a } \\
\text { realização de uma determinada atividade }\end{array}$ & $\begin{array}{l}\text { Rezende et al } \\
\qquad(2013)\end{array}$ \\
\hline Estoque & $\begin{array}{l}\text { É o desperdício devido ao excesso de matérias- } \\
\text { primas ou de produtos acabados }\end{array}$ & $\begin{array}{l}\text { Liker e Meier } \\
\qquad(2007)\end{array}$ \\
\hline Transporte & $\begin{array}{l}\text { Excesso de movimentação de materiais dentro } \\
\text { da empresa que não agrega valor ao produto }\end{array}$ & Slack (2009) \\
\hline
\end{tabular}

Figura 1. Definição dos sete tipos de desperdícios

Fonte: Próprio autor.

A identificação desses desperdícios dentro do processo de produção é o primeiro passo para a redução dessas atividades, aumento da produtividade e da competitividade do empreendimento. Para que esse processo seja realizado, faz-se necessário a utilização de ferramentas enxutas.

\subsubsection{Ferramentas da produção enxuta}

As ferramentas da produção enxuta são destacadas na sequência, com o objetivo de empregá-las no levantamento dos processos e na apuração dos tempos de execução.

a) Diagrama de Fluxo do Processo

A melhor maneira de entender um processo é mapeando-o, pois a representação visual das atividades facilita a identificação de melhorias. Barnes (1982) afirma que a partir da análise do processo é possível reduzir e eliminar o trabalho desnecessário, 
Avaliação de Custos e Desperdícios na linha de Produção de Tortas Promocionais em uma Indústria de Alimentos

Carla Andréa Mendonça de Albuquerque, Maria Silene Alexandre Leite, Stela de Lourdes Ribeiro de Mendonça

combinar operações ou elementos, assim como modificar a sequência das operações e simplificar as operações essenciais.

O mapeamento pode ser realizado de diferentes formas, dentre elas o diagrama de fluxo vertical. Para Nascimento (2012), o estudo do fluxo de produção de forma vertical é utilizado para analisar os processos produtivos que apresentam rotinas simples.

b) Cronoanálise

De acordo com Sugai (2003), através do estudo do tempo o Frederic W. Taylor, verificou-se que a racionalização de operações auxilia na eliminação de movimentos inúteis, tal processo garante a redução de custo em consequência da economia de tempos e gastos com operários. O casal Frank e Lilian seguiram essa mesma linha de raciocínio e desenvolveram técnicas de estudos dos movimentos através da cronoanálise que tem como propósito três funções, tais como evitar os movimentos inúteis na execução de uma tarefa; executar o mais economicamente possível e dar a esses movimentos selecionados uma seriação apropriada.

A partir do estudo de tempos, movimentos e análise da melhor forma de execução das atividades é possível obter o tempo padrão. Esse número se trata do período em que um funcionário devidamente capacitado realiza uma determinada atividade padronizada. O tempo padrão é de grande relevância nos cálculos realizados para levantamento de custo de mão de obra, auxiliando no processo de PCP (Barnes, 2004).

Peinado e Graeml (2007) afirmam que para a realização da cronoanálise é necessária a aplicação de três etapas:

a) Determinação do tempo cronometrado

Primeiramente a operação deve ser dividida em partes, de forma que se torne possível cronometrar cada etapa do processo de fabricação do produto. Dessa forma, faz-se necessário a separação de atividades realizadas pela máquina das efetuadas pelos operadores, devendo ser feita uma análise particular. Para determinação do 
Avaliação de Custos e Desperdícios na linha de Produção de Tortas Promocionais em uma Indústria de Alimentos

Carla Andréa Mendonça de Albuquerque, Maria Silene Alexandre Leite, Stela de Lourdes Ribeiro de Mendonça

tempo de atividade é necessário realizar uma série de cronometragens de cada etapa, para que se tenha o número necessário de ciclos a serem cronometrados se utiliza o cálculo estatístico apresentados na Equação 3:

$$
N=\left(\frac{Z \times R}{E r \times d^{2} \times X}\right)^{2}
$$

Onde:

$\mathrm{N}=$ Número de ciclos a serem cronometrados;

$\mathrm{Z}=$ Coeficiente de distribuição normal para uma probabilidade determinada

$\mathrm{R}=$ Amplitude da amostra;

Er=Erro relativo da medida;

d2= Coeficiente em função do número de cronometragem realizadas preliminarmente.

O erro relativo da medida (Er) pode variar de 5 a 10\%, já a amplitude da amostra é obtida através da cronometragem do tempo. O valor de $Z$ (Coeficiente de distribuição normal) de acordo com uma probabilidade determinada que pode variar de 90 a $99 \%$, como mostra a Tabela 1 (Peinado \& Graeml, 2007).

Tabela 1

Coeficiente de distribuição

\begin{tabular}{lcccccccccc}
\hline \multirow{2}{*}{ PROBABILIDADE } & \multirow{2}{*}{$90 \%$} & 91 & $\mathbf{9 2}$ & $\mathbf{9 3}$ & $\mathbf{9 4}$ & $\mathbf{9 5}$ & $\mathbf{9 6}$ & $\mathbf{9 7}$ & $\mathbf{9 8}$ & $\mathbf{9 9}$ \\
& & $\%$ & $\%$ & $\%$ & $\%$ & $\%$ & $\%$ & $\%$ & $\%$ & $\%$ \\
\hline \multirow{2}{*}{$\mathrm{Z}$} & \multirow{2}{*}{1,65} & 1,7 & 1,7 & 1, & 1, & 1, & 2, & 2,1 & 2,3 & 2,5 \\
& & 0 & 5 & 81 & 88 & 96 & 05 & 7 & 3 & 8 \\
\hline
\end{tabular}

Nota. Fonte: Peinado \& Graeml (2007).

É notório que, quanto maior for o grau de confiança, maior será o valor de Z, essa constatação permite afirmar que como consequência o d2 também irá aumentar, posto que, o valor de $Z$ na Equação 1 é diretamente proporcional ao valor do 
Avaliação de Custos e Desperdícios na linha de Produção de Tortas Promocionais em uma Indústria de Alimentos

Carla Andréa Mendonça de Albuquerque, Maria Silene Alexandre Leite, Stela de Lourdes Ribeiro de Mendonça

Coeficiente em função do número de cronometragens $(\mathrm{N})$, como se pode ver na Tabela 2.

Tabela 2

Coeficiente em função

\begin{tabular}{lclccccccc}
\hline $\mathbf{N}$ & $\mathbf{2}$ & $\mathbf{3}$ & $\mathbf{4}$ & $\mathbf{5}$ & $\mathbf{6}$ & $\mathbf{7}$ & $\mathbf{8}$ & $\mathbf{9}$ & $\mathbf{1 0}$ \\
\hline $\mathrm{d} 2$ & 1,128 & 1,693 & 2,059 & 2,326 & 2,534 & 2,704 & 2,847 & 2,970 & 3,078 \\
\hline
\end{tabular}

Nota. Fonte: Peinado \& Graeml (2007).

a) Determinação do tempo normal

A velocidade do operador é definida pelo cronoanalista de forma subjetiva de acordo com o seu ritmo de trabalho. A avaliação não considera fatores como a intimidação por estar sendo observado, como a fadiga no início ou fim de expediente e outras variáveis. De acordo com Peinado e Graeml (2007), o tempo normal (TN) para realização de uma atividade é determinado através do tempo cronometrado (TC) em função da velocidade do operador (v).

b) Determinação do tempo padrão

Levando em consideração que não há possibilidade de os operadores trabalharem em um mesmo ritmo (tempo normal) durante todo o dia, então se faz necessário a determinação de um tempo padrão que é calculado por meio da multiplicação do tempo normal pelo fator de tolerância. O fator de tolerância (FT) depende do tempo de permissão que a empresa concede aos seus funcionários. Sendo assim é calculada através da Equação 4:

$$
\mathrm{FT}=1 /(1-\mathrm{P})
$$

Onde:

$\mathrm{FT}=$ Fator de tolerância

$\mathrm{P}=$ Tempo de intervalo dado dividido pelo tempo de trabalho 
Avaliação de Custos e Desperdícios na linha de Produção de Tortas Promocionais em uma Indústria de Alimentos

Carla Andréa Mendonça de Albuquerque, Maria Silene Alexandre Leite, Stela de Lourdes Ribeiro de Mendonça

Esta seção tratou dos custos gerenciais associados ao levantamento e à gestão dos desperdícios, segundo a lógica do Lean Manufacturing. A cronoanálise e o diagrama do fluxo de processo foram abordados como ferramentas auxiliares no processo de identificação das atividades que não agregam valor ao produto.

O estudo de Costa (2017) mostrou que em tempos econômicos escassos, as empresas podem utilizar os métodos de produção enxuta para reduzir os desperdícios e alcançar uma maior produtividade em seus processos. Sendo que, através dessa iniciativa, as indústrias podem aumentar a competitividade e alcançar melhores resultados reduzindo seus custos.

O diagrama de fluxo foi utilizado em um estudo de caso de uma indústria do setor alimentício através do trabalho "Ferramentas da Qualidade na Identificação de Desperdícios e suas Causas" para auxiliar a coleta de dados e no sequenciamento das operações realizadas na fabricação de cinco tipos de produtos da panificação. A partir dessa análise, possibilitou-se constatar que através da eliminação do desperdício por superprodução desses produtos pode reduzir em $67,6 \%$ o custo de matéria-prima (Milani et al., 2016).

\section{PROCEDIMENTOS METODOLÓGICOS}

Esta pesquisa foi classificada como aplicada, por meio do estudo de caso exploratório, com intenção de obter os objetivos propostos. Yin (2015) relata que o estudo de caso é uma investigação na prática, de um fenômeno, em seu contexto, de forma aprofundada.

De acordo com Pádua (2019), a pesquisa qualitativa tem como finalidade a interpretação dos parâmetros de sentido e relevância dos dados obtidos, tendo a observação e interpretação da realidade em estudo com objetivo, através de procedimentos metodológicos variados e a busca de explicações alternativas que gerem exemplos e/ou comparação. 
Avaliação de Custos e Desperdícios na linha de Produção de Tortas Promocionais em uma Indústria de Alimentos

Carla Andréa Mendonça de Albuquerque, Maria Silene Alexandre Leite, Stela de Lourdes Ribeiro de Mendonça

O estudo de caso foi aplicado em uma indústria no ramo da panificação e confeitaria localizada na cidade de João Pessoa - PB. Essa empresa foi selecionada devido a disponibilidade de acesso aos dados e interesse dos proprietários no desenvolvimento do trabalho. Nessa empresa são produzidos uma grande variedade de produtos que podem ser doces ou salgados. Os salgados são divididos entre salgadinhos de festas que são vendidos por cento e salgados que são expostos em balcão para lanche, sendo vendidos por unidade. Os doces podem ser sobremesas, docinhos, tortas promocionais e tortas especiais. As tortas promocionais são o produto objeto de estudo deste trabalho.

Para realização da coleta de dados empregou-se a pesquisa em documentos, a aplicação formulários e a observação da rotina da empresa. A análise dos dados coletados foi realizada com o auxílio das ferramentas de diagrama de fluxo de valor e da cronoanálise. Os tratamentos estatísticos foram efetuados através do editor de planilhas Microsoft Office Excel 365 (2019).

Inicialmente, para identificação dos custos de matéria-prima, foi necessário utilizar um formulário com todos os ingredientes necessários para fabricação de cada torta para obtenção da quantidade real utilizada na fabricação (Figura 2).

\begin{tabular}{|c|c|c|c|c|c|}
\hline \multirow{2}{*}{\multicolumn{2}{|c|}{$\begin{array}{l}\text { LOGO } \\
\text { EMPRESA }\end{array}$}} & \multicolumn{4}{|c|}{ Formulário de caracterização do produto } \\
\hline & & Produto: & & & \\
\hline \multicolumn{2}{|c|}{$\begin{array}{c}\mathrm{N}^{\circ} \text { de funcionários } \\
\text { envolvidos: }\end{array}$} & \multirow[b]{2}{*}{$\begin{array}{c}\text { QUANTIDADE } \\
\text { BRUTA }\end{array}$} & \multicolumn{2}{|c|}{ Rendimento: } & \multirow[b]{2}{*}{$\begin{array}{l}\text { CUSTO/ } \\
\text { PORÇÃOO }\end{array}$} \\
\hline MP & UNIDADE & & $\begin{array}{l}\text { QUANTIDADE } \\
\text { LIQUIDA }\end{array}$ & $\begin{array}{c}\text { CUSTO } \\
\text { UNITÁRIO }\end{array}$ & \\
\hline & & & & & \\
\hline & & & & & \\
\hline
\end{tabular}

Figura 2. Formulário para obtenção de dados

Fonte: Próprio autor. 
Avaliação de Custos e Desperdícios na linha de Produção de Tortas Promocionais em uma Indústria de Alimentos

Carla Andréa Mendonça de Albuquerque, Maria Silene Alexandre Leite, Stela de Lourdes Ribeiro de Mendonça

Esse formulário foi utilizado em todo o processo, em turnos distintos e com funcionários diferentes que realizam a mesma atividade. Além disso, utilizou-se a relação de compras efetuadas pela empresa durante um período de três meses para a obtenção dos preços de compra das matérias-primas.

O custo de mão de obra foi baseado no tempo padrão de atividade do operador na realização de cada unidade de torta. Para encontrar o tempo padrão da produção foi necessário realizar uma cronoanálise, para tanto, este estudo foi dividido em sete etapas, sendo elas: obtenção das informações sobre a operação; divisão das operações em elementos; observação e registro do tempo gasto pelo operador; determinação do número de ciclos; avaliação do ritmo do operador; determinação da tolerância; e determinação do tempo padrão.

As atividades foram divididas em cinco elementos de operação, como a produção da massa, produção do recheio, montagem, finalização e reprocesso. Com exceção da torta com sabor de limão, que não possui a etapa de reprocesso, posto que, em sua produção não é adicionada a farinha proveniente do reprocesso.

Para efeitos deste estudo foram realizadas de cinco a dez tomadas de tempos por elemento para a determinação da quantidade de ciclos a serem cronometrados. 0 tempo gasto com cada operação foi obtido levando em consideração a análise da situação em condições normais de trabalho. O custo de energia foi calculado de acordo com a potência e o tempo de utilização das máquinas para a fabricação de uma unidade.

Para a depreciação utilizou-se o método linear que de acordo com Silva (2016), considera que o bem a cada ano deprecia o mesmo valor, a fórmula utilizada para esse cálculo é a idade atual do imóvel dividida pelo número de anos de vida útil do mesmo. Para o número de anos de vida útil do imóvel (n), utilizou-se uma taxa de depreciação de $10 \%$ ao ano para máquinas e $5 \%$ para equipamentos utilizados pela área administrativa. O custo de manutenção foi calculado de acordo com o tempo estimado pelo supervisor da produção de manutenção em cada setor e com os gastos com peças, durante período de três meses, foram repassados pela empresa. 
Avaliação de Custos e Desperdícios na linha de Produção de Tortas Promocionais em uma Indústria de Alimentos

Carla Andréa Mendonça de Albuquerque, Maria Silene Alexandre Leite, Stela de Lourdes Ribeiro de Mendonça

As despesas mensais foram repassadas pela contabilidade da empresa. $\mathrm{O}$ montante total dessas despesas, sem separação por tipo, foi dividido pela quantidade de produtos comercializados pela empresa e sua respectiva representatividade no faturamento mensal. A partir da obtenção dos custos diretos e indiretos foi possível calcular o custo gerencial.

A identificação dos desperdícios foi realizada a partir das etapas de observação da linha de produção de tortas; do levantamento de todas as operações envolvidas; da divisão das operações em atividades; da elaboração de formulários; do preenchimento de formulário; da análise de cada atividade conforme a agregação de valor e da classificação dos desperdícios.

O diagrama de fluxo do processo foi preenchido inicialmente com as operações que foram subdivididas em atividades. Logo após, essas atividades foram caracterizadas como transporte, espera, operação ou armazenamento e os símbolos que representam cada parâmetro foi preenchido. Cada atividade foi descrita de forma minuciosa para que assim pudessem ser classificadas em "agrega valor", "não agrega valor, mas é necessária" e "desperdício". Por fim, as classificações foram somadas.

\section{APRESENTAÇÃO E ANÁLISE dOS RESULTADOS}

\subsection{Caracterização da empresa}

A indústria de pequeno porte atua no mercado de alimentos de João Pessoa -PB há 28 anos, atualmente ela possui em média 50 funcionários, distribuídos em dois turnos de trabalho, $4.000 \mathrm{~m}^{2}$ de área divididos em seis setores, duas lojas afiliadas e seis franqueadas. O Quadro 2 apresenta missão, visão e valores da empresa em estudo.

A linha de produção de tortas são subdivididas de acordo com seu sabor, cobertura e tamanho. Os sabores oferecidos são: chocolate, crocante, mista, maracujá e limão. A cobertura pode ser de chocolate ou de marshmellow. Além disso, as tortas são divididas em três tamanho, totalizando dessa forma a variação de 30 tipos de tortas 
Avaliação de Custos e Desperdícios na linha de Produção de Tortas Promocionais em uma Indústria de Alimentos

Carla Andréa Mendonça de Albuquerque, Maria Silene Alexandre Leite, Stela de Lourdes Ribeiro de Mendonça

promocionais oferecidos no cardápio da empresa a seus clientes. As tortas de tamanho 1 apresentam peso médio de $975 \mathrm{~g}$ e diâmetro de $16 \mathrm{~cm}$, as tortas de tamanho 2 possuem peso médio de $1.553 \mathrm{~g}$ e diâmetro de $19 \mathrm{~cm}$, já as tortas de tamanho 3 possuem $25,5 \mathrm{~cm}$ de diâmetro e peso médio de $2.293 \mathrm{~g}$.

É possível notar que as tortas promocionais representam $36 \%$ do faturamento total mensal de $\mathrm{R} \$ 228.867,00$ (100\%). Dentro desse segmento existem apenas seis tipos de tortas, essas variam de preço de acordo com seu tamanho e tipo de cobertura. Nesse contexto, a Tabela 3 mostra a representatividade de cada torta em função do seu segmento.

Tabela 3

Representatividade de cada tipo de torta

\begin{tabular}{cccc}
\hline Tamanho & Cobertura & Faturamento Mensal & Representatividade (\%) \\
\hline 1 & Marshmellow & $\mathrm{R} \$ 21.351,90$ & 9,3 \\
2 & Marshmellow & $\mathrm{R} \$ 10.019,80$ & 4,4 \\
3 & Marshmellow & $\mathrm{R} \$ 23.595,80$ & 10,3 \\
1 & Chocolate & $\mathrm{R} \$ 10.530,90$ & 4,6 \\
2 & Chocolate & $\mathrm{R} \$ 6.330,50$ & 2,8 \\
3 & Chocolate & $\mathrm{R} \$ 10.327,00$ & 4,5 \\
\hline
\end{tabular}

Nota. Fonte: Próprio autor.

O tipo de torta com maior representatividade em seu segmento é a tamanho 3 de cobertura de Marshmellow com 10,3\% do total de 36\%. Em contraponto, a torta de chocolate tamanho 2 apresentou uma representatividade de 2,8\%. A obtenção desses dados é de grande relevância no processo de alocação de custos indiretos e despesas através da representatividade dessa alocação que pode ser realizada de forma adequada. 
Avaliação de Custos e Desperdícios na linha de Produção de Tortas Promocionais em uma Indústria de Alimentos

Carla Andréa Mendonça de Albuquerque, Maria Silene Alexandre Leite, Stela de Lourdes Ribeiro de Mendonça

\subsection{Sistema de produção}

a) Diagrama de Fluxo do Processo

O diagrama do processo permite o registro de um processo de forma simplificada e padronizada para facilitar a sua análise e posterior melhoria (Barnes, 1982). Todas as movimentações realizadas entre os setores envolvidos (cocção, confeitaria e estoque) foram consideradas como operações de transporte. As operações de espera ocorrem com o produto acabado, quando ainda se encontra no setor da confeitaria e aguarda demanda de outras lojas ou franquias, assim como quando o produto se encontra em processo e aguarda a próxima operação. A inspeção é realizada na operação de contagem de tortas em estoque e na emissão da ordem de produção diária. Para as atividades de estocagem de produto em processo ou de produto acabado foram relacionadas com a simbologia de armazenamento. Através do diagrama do fluxo de processo e da sua simbologia foi possível identificar atividades que não agregam valor e classificá-las através de formulários.

b) Cronoanálise

O desempenho demonstrado pelo trabalhador foi julgado através da observação, buscando a confiabilidade de $90 \%$ igual a 1,65 , erro de $5 \%$ e ritmo de $100 \%$. O cronometrista avaliou o ritmo do funcionário, baseando-se em seus conhecimentos prévios da operação. Após multiplicar o tempo médio observado pelo ritmo do colaborador, obteve-se o tempo normal. A cronoanálise foi utilizada como ferramenta auxiliar na determinação do cálculo do custo de mão de obra.

A Tabela 4 mostra os resultados encontrados do tempo normal para a fabricação dos 30 tipos de tortas em estudo. 
Avaliação de Custos e Desperdícios na linha de Produção de Tortas Promocionais em uma Indústria de Alimentos Carla Andréa Mendonça de Albuquerque, Maria Silene Alexandre Leite, Stela de Lourdes Ribeiro de Mendonça

Tabela 4

Tempo normal de produção de tortas

\begin{tabular}{lcccc}
\hline Sabor & Tamanho 1 & Tamanho 2 & Tamanho 3 & Cobertura \\
\hline Chocolate & 22,0 & 27,4 & 39,7 & Chocolate \\
Chocolate & 17,4 & 20,5 & 25,4 & Marshmellow \\
Maracujá & 19,8 & 25,9 & 36,0 & Chocolate \\
Maracujá & 16,4 & 19,0 & 22,9 & Marshmellow \\
Limão & 14,2 & 18,3 & 26,4 & Chocolate \\
Limão & 11,9 & 14,9 & 20,7 & Marshmellow \\
Crocante & 23,3 & 29,1 & 41,7 & Chocolate \\
Crocante & 16,0 & 20,8 & 27,5 & Marshmellow \\
Mista & 23,4 & 29,4 & 37,6 & Chocolate \\
Mista & 16,8 & 21,8 & 29,0 & Marshmellow \\
\hline
\end{tabular}

Nota. Fonte: Próprio autor.

A Tabela 5 mostra os resultados encontrados do tempo padrão para a fabricação dos 30 tipos de tortas em estudo.

Tabela 5

Tempo padrão de produção de tortas

\begin{tabular}{lcccc}
\hline Sabor & Tamanho 1 & Tamanho 2 & Tamanho 3 & Cobertura \\
\hline Chocolate & 26,4 & 32,9 & 47,7 & Chocolate \\
Chocolate & 20,8 & 24,6 & 30,5 & Marshmellow \\
Maracujá & 23,8 & 31,1 & 43,2 & Chocolate \\
Maracujá & 19,6 & 22,8 & 27,4 & Marshmellow \\
Limão & 17,1 & 22,0 & 31,6 & Chocolate \\
Limão & 14,3 & 17,9 & 24,9 & Marshmellow \\
Crocante & 28,0 & 35,0 & 50,0 & Chocolate \\
Crocante & 19,2 & 25,0 & 33,0 & Marshmellow \\
Mista & 28,1 & 35,3 & 45,1 & Chocolate \\
Mista & 20,2 & 26,2 & 34,8 & Marshmellow \\
\hline
\end{tabular}

Nota. Fonte: Próprio autor.

Através da mensuração do tempo padrão foi possível identificar os gargalos da produção das tortas promocionais. A torta com cobertura de chocolate possui uma textura mais consistente e, desse modo, faz-se necessário um maior cuidado na 
Avaliação de Custos e Desperdícios na linha de Produção de Tortas Promocionais em uma Indústria de Alimentos

Carla Andréa Mendonça de Albuquerque, Maria Silene Alexandre Leite, Stela de Lourdes Ribeiro de Mendonça

aplicação sobre a massa para que essa não se quebre. Esse fato explica um maior tempo padrão quando comparado com a cobertura de marshmellow, bem como o elevado tempo na produção das tortas de sabor chocolate.

\subsection{Identificação de custos e despesas no processo de produção de tortas promocionais}

a) Custos Diretos

Através da coleta de todos os ingredientes utilizados na fabricação das tortas, por intermédio do preço médio de compra e baseado em uma avaliação de três meses subsequentes, possibilitou calcular o custo de matéria-prima na fabricação de cada tipo de torta, como mostra a Tabela 6.

Tabela 6

Custo de matéria-prima por unidade produzida

\begin{tabular}{lllll}
\hline Sabor & Cobertura & $\begin{array}{c}\text { Tamanho 1 } \\
\text { (R\$/un) }\end{array}$ & $\begin{array}{c}\text { Tamanho 2 } \\
\text { (R\$/un) }\end{array}$ & $\begin{array}{c}\text { Tamanho } \\
\mathbf{3 ( R} \mathbf{R} / \mathbf{u n})\end{array}$ \\
\hline Maracujá & Marshmellow & $\mathrm{R} \$ 12,15$ & $\mathrm{R} \$ 15,26$ & $\mathrm{R} \$ 19,79$ \\
Maracujá & Chocolate & $\mathrm{R} \$ 13,23$ & $\mathrm{R} \$ 16,98$ & $\mathrm{R} \$ 21,77$ \\
Crocante & Marshmellow & $\mathrm{R} \$ 9,71$ & $\mathrm{R} \$ 15,05$ & $\mathrm{R} \$ 17,25$ \\
Crocante & Chocolate & $\mathrm{R} \$ 13,64$ & $\mathrm{R} \$ 23,94$ & $\mathrm{R} \$ 24,22$ \\
Chocolate & Marshmellow & $\mathrm{R} \$ 11,66$ & $\mathrm{R} \$ 14,36$ & $\mathrm{R} \$ 18,95$ \\
Chocolate & Chocolate & $\mathrm{R} \$ 14,01$ & $\mathrm{R} \$ 17,85$ & $\mathrm{R} \$ 23,86$ \\
Mista & Marshmellow & $\mathrm{R} \$ 10,02$ & $\mathrm{R} \$ 14,11$ & $\mathrm{R} \$ 18,82$ \\
Mista & Chocolate & $\mathrm{R} \$ 12,97$ & $\mathrm{R} \$ 21,07$ & $\mathrm{R} \$ 27,57$ \\
Limão & Marshmellow & $\mathrm{R} \$ 9,54$ & $\mathrm{R} \$ 13,27$ & $\mathrm{R} \$ 17,82$ \\
Limão & Chocolate & $\mathrm{R} \$ 13,65$ & $\mathrm{R} \$ 18,79$ & $\mathrm{R} \$ 23,68$ \\
\hline
\end{tabular}

Nota. Fonte: Próprio autor.

A mão de obra foi composta por cinco operadores na produção das tortas de todos os sabores, com exceção das tortas de limão que apresentaram 4 operadores, pois não possui a etapa de reprocesso da farinha. Nos cálculos da mão de obra (Tabela 7) foram considerados os salários dos operadores mais os encargos previstos em lei e alocados de acordo com o tempo de dedicação do funcionário durante a produção. 
Avaliação de Custos e Desperdícios na linha de Produção de Tortas Promocionais em uma Indústria de Alimentos Carla Andréa Mendonça de Albuquerque, Maria Silene Alexandre Leite, Stela de Lourdes Ribeiro de Mendonça

Tabela 7

Custo de mão de obra por unidade produzida

\begin{tabular}{lcccc}
\hline Sabor & Cobertura & $\begin{array}{c}\text { Tamanho 1 } \\
\text { (R\$/un) }\end{array}$ & $\begin{array}{c}\text { Tamanho 2 } \\
\text { (R\$/un) }\end{array}$ & $\begin{array}{c}\text { Tamanho 3 } \\
\text { (R\$/un) }\end{array}$ \\
\hline Chocolate & Chocolate & $\mathrm{R} \$ 2,97$ & $\mathrm{R} \$ 3,71$ & $\mathrm{R} \$ 5,35$ \\
Chocolate & Marshmellow & $\mathrm{R} \$ 2,38$ & $\mathrm{R} \$ 2,81$ & $\mathrm{R} \$ 3,50$ \\
Maracujá & Chocolate & $\mathrm{R} \$ 2,69$ & $\mathrm{R} \$ 3,51$ & $\mathrm{R} \$ 4,86$ \\
Maracujá & Marshmellow & $\mathrm{R} \$ 2,24$ & $\mathrm{R} \$ 2,62$ & $\mathrm{R} \$ 3,16$ \\
Crocante & Chocolate & $\mathrm{R} \$ 3,15$ & $\mathrm{R} \$ 3,93$ & $\mathrm{R} \$ 5,62$ \\
Crocante & Marshmellow & $\mathrm{R} \$ 2,19$ & $\mathrm{R} \$ 2,84$ & $\mathrm{R} \$ 3,72$ \\
Mista & Chocolate & $\mathrm{R} \$ 3,17$ & $\mathrm{R} \$ 3,97$ & $\mathrm{R} \$ 5,08$ \\
Mista & Marshmellow & $\mathrm{R} \$ 2,30$ & $\mathrm{R} \$ 2,97$ & $\mathrm{R} \$ 3,92$ \\
Limão & Chocolate & $\mathrm{R} \$ 1,90$ & $\mathrm{R} \$ 2,42$ & $\mathrm{R} \$ 3,49$ \\
Limão & Marshmellow & $\mathrm{R} \$ 1,90$ & $\mathrm{R} \$ 2,42$ & $\mathrm{R} \$ 3,49$ \\
\hline
\end{tabular}

Nota. Fonte: Próprio autor.

b) Custos Indiretos

Para o custo de depreciação considerou-se as máquinas e equipamentos utilizadas no setor de confeitaria e cocção e os equipamentos utilizados pelos setores administrativos da empresa. Para encontrar a depreciação mensal de cada setor foi necessário somar a depreciação mensal de cada equipamento e/ou máquina utilizados por esse.

Tendo em vista que os equipamentos das áreas administrativas são utilizados em função de todos os segmentos de produtos e não apenas pelas tortas promocionais, o valor mensal de depreciação desse setor foi dividido pelos sete segmentos de produtos ofertados pela empresa.

A alocação do custo de depreciação para cada unidade produzida de torta, de acordo com seu tipo, foi realizada considerando a sua representatividade em seu segmento e dividindo pela produção média mensal apresentada na Tabela 8. 
Avaliação de Custos e Desperdícios na linha de Produção de Tortas Promocionais em uma Indústria de Alimentos Carla Andréa Mendonça de Albuquerque, Maria Silene Alexandre Leite, Stela de Lourdes Ribeiro de Mendonça

Tabela 8

Custo de depreciação por unidade produzida

\begin{tabular}{lccccc}
\hline Cobertura & Tamanho & Faturamento (\%) & Depreciação & $\begin{array}{c}\text { Produção } \\
\text { mensal }\end{array}$ & Custo/ un \\
\hline Marshmellow & 1 & 0,25 & 214,26 & 734,3 & $\mathrm{R} \$ 0,29$ \\
Marshmellow & 2 & 0,12 & 100,55 & 278,0 & $\mathrm{R} \$ 0,36$ \\
Marshmellow & 3 & 0,28 & 236,78 & 437,3 & $\mathrm{R} \$ 0,54$ \\
Chocolate & 1 & 0,13 & 105,67 & 286,0 & $\mathrm{R} \$ 0,37$ \\
Chocolate & 2 & 0,08 & 63,52 & 138,7 & $\mathrm{R} \$ 0,46$ \\
Chocolate & 3 & 0,12 & 103,63 & 151,0 & $\mathrm{R} \$ 0,69$ \\
\hline
\end{tabular}

Nota. Fonte: Próprio autor.

Para o custo de manutenção foi considerado o tempo médio do operador em cada setor e os gastos que a empresa realizou durante um período de cinco meses. $O$ custo total de manutenção, incluindo os gastos com peças e o custo da mão de obra do operador, foram repassados para o produto de acordo com o faturamento de cada produto e sua média de produção mensal como mostra a Tabela 9.

Tabela 9

Custo de manutenção por unidade produzida

\begin{tabular}{lccccc}
\hline Cobertura & Tamanho & $\begin{array}{c}\text { Representatividade } \\
(\%)\end{array}$ & $\begin{array}{c}\text { Custo/ } \\
\text { mês }\end{array}$ & $\begin{array}{c}\text { Produção } \\
\text { mensal }\end{array}$ & Custo/ un \\
\hline Marshmellow & 1 & 0,16 & 396,56 & 734,33 & 0,54 \\
Marshmellow & 2 & 0,08 & 186,09 & 278,00 & 0,67 \\
Marshmellow & 3 & 0,18 & 438,23 & 437,33 & 1,00 \\
Chocolate & 1 & 0,08 & 195,59 & 286,00 & 0,68 \\
Chocolate & 2 & 0,05 & 117,57 & 138,67 & 0,85 \\
Chocolate & 3 & 0,08 & 191,80 & 151,00 & 1,27 \\
\hline
\end{tabular}

Nota. Fonte: Próprio autor.

A energia elétrica foi calculada de acordo com o tempo de utilização dos equipamentos e seu consumo. O preço da tarifa B3 classificada como industrial é de $R \$$ 0,57177/kwh (Energisa, 2019). 
Avaliação de Custos e Desperdícios na linha de Produção de Tortas Promocionais em uma Indústria de Alimentos Carla Andréa Mendonça de Albuquerque, Maria Silene Alexandre Leite, Stela de Lourdes Ribeiro de Mendonça

Tabela 10

Custo de energia por unidade produzida

\begin{tabular}{lcccc}
\hline Sabor & Cobertura & Tamanho 1 & Tamanho 2 & Tamanho 3 \\
\hline Chocolate & Marshmellow & $\mathrm{R} \$ 2,07$ & $\mathrm{R} \$ 1,29$ & $\mathrm{R} \$ 1,51$ \\
Chocolate & Chocolate & $\mathrm{R} \$ 1,88$ & $\mathrm{R} \$ 1,94$ & $\mathrm{R} \$ 2,06$ \\
Mista & Marshmellow & $\mathrm{R} \$ 1,85$ & $\mathrm{R} \$ 1,90$ & $\mathrm{R} \$ 2,00$ \\
Mista & Chocolate & $\mathrm{R} \$ 2,01$ & $\mathrm{R} \$ 2,17$ & $\mathrm{R} \$ 2,38$ \\
Maracujá & Marshmellow & $\mathrm{R} \$ 2,04$ & $\mathrm{R} \$ 2,02$ & $\mathrm{R} \$ 2,15$ \\
Maracujá & Chocolate & $\mathrm{R} \$ 1,95$ & $\mathrm{R} \$ 2,04$ & $\mathrm{R} \$ 2,16$ \\
Limão & Marshmellow & $\mathrm{R} \$ 1,91$ & $\mathrm{R} \$ 2,02$ & $\mathrm{R} \$ 2,15$ \\
Limão & Chocolate & $\mathrm{R} \$ 1,95$ & $\mathrm{R} \$ 2,04$ & $\mathrm{R} \$ 2,16$ \\
Crocante & Marshmellow & $\mathrm{R} \$ 1,79$ & $\mathrm{R} \$ 1,83$ & $\mathrm{R} \$ 1,88$ \\
Crocante & Chocolate & $\mathrm{R} \$ 1,91$ & $\mathrm{R} \$ 2,01$ & $\mathrm{R} \$ 2,08$ \\
\hline
\end{tabular}

Nota. Fonte: Próprio autor.

\section{c) Despesas}

Os itens de despesa praticados pela empresa foram inicialmente divididos pelos seis tipos de segmentos de produtos de acordo com sua representatividade do faturamento da empresa, dentre eles o segmento de tortas promocionais e seus respectivos tipos de cobertura e tamanhos, nesse caso o sabor da torta não influencia no resultado final.

Tabela 11

Despesas por unidade produzida

\begin{tabular}{lccccc}
\hline Cobertura & Tamanho & $\begin{array}{c}\text { Representati } \\
\text { vidade (\%) }\end{array}$ & Despesa & $\begin{array}{c}\text { Produção } \\
\text { mensal }\end{array}$ & espesa/ un \\
\hline Marshmellow & 1 & 0,16 & $\mathrm{R} \$ 752,27$ & 734 & $\mathrm{R} \$ 1,02$ \\
Marshmellow & 2 & 0,08 & $\mathrm{R} \$ 353,02$ & 278 & $\mathrm{R} \$ 1,27$ \\
Marshmellow & 3 & 0,18 & $\mathrm{R} \$ 831,33$ & 437 & $\mathrm{R} \$ 1,90$ \\
Chocolate & 1 & 0,08 & $\mathrm{R} \$ 371,03$ & 286 & $\mathrm{R} \$ 1,30$ \\
Chocolate & 2 & 0,05 & $\mathrm{R} \$ 223,04$ & 139 & $\mathrm{R} \$ 1,61$ \\
Chocolate & 3 & 0,08 & $\mathrm{R} \$ 363,84$ & 151 & $\mathrm{R} \$ 2,41$ \\
\hline
\end{tabular}

Nota. Fonte: Próprio autor. 
Avaliação de Custos e Desperdícios na linha de Produção de Tortas Promocionais em uma Indústria de Alimentos

Carla Andréa Mendonça de Albuquerque, Maria Silene Alexandre Leite, Stela de Lourdes Ribeiro de Mendonça

d) Custo Gerencial

Após a obtenção dos custos diretos, indiretos e despesas foi realizado a soma desses resultou no custo gerencial das tortas promocionais. A Tabela 12 apresenta os resultados encontrados de custo gerencial para tortas de tamanho 1, assim como o custo que a empresa utiliza para formação do preço de venda.

Tabela 12

Custo gerencial de tortas tamanho 1

\begin{tabular}{lcl}
\hline Sabor & Cobertura & Custo Gerencial \\
\hline Maracujá & Chocolate & $\mathrm{R} \$ 19,38$ \\
Maracujá & Marshmellow & $\mathrm{R} \$ 17,32$ \\
Chocolate & Chocolate & $\mathrm{R} \$ 20,56$ \\
Chocolate & Marshmellow & $\mathrm{R} \$ 16,93$ \\
Crocante & Chocolate & $\mathrm{R} \$ 20,21$ \\
Crocante & Marshmellow & $\mathrm{R} \$ 14,71$ \\
Mista & Chocolate & $\mathrm{R} \$ 19,66$ \\
Mista & Marshmellow & $\mathrm{R} \$ 15,18$ \\
Limão & Chocolate & $\mathrm{R} \$ 19,01$ \\
Limão & Marshmellow & $\mathrm{R} \$ 14,36$ \\
\hline
\end{tabular}

Nota. Fonte: Próprio autor.

Por meio da soma do custo gerencial total das tortas tamanho 1 foram encontrados os custos com matéria-prima que representam $68 \%$, o de mão de obra direta $14 \%$ e o de energia $11 \%$. O restante está dividido entre os custos de manutenção, depreciação e despesas. A Tabela 13 mostra o custo gerencial das tortas tamanho 2. 
Avaliação de Custos e Desperdícios na linha de Produção de Tortas Promocionais em uma Indústria de Alimentos Carla Andréa Mendonça de Albuquerque, Maria Silene Alexandre Leite, Stela de Lourdes Ribeiro de Mendonça

Tabela 13

Custo gerencial de tortas tamanho 2

\begin{tabular}{lcc}
\hline Sabor & Cobertura & Custo Gerencial \\
\hline Maracujá & Chocolate & $\mathrm{R} \$ 24,60$ \\
Maracujá & Marshmellow & $\mathrm{R} \$ 21,35$ \\
Chocolate & Chocolate & $\mathrm{R} \$ 25,76$ \\
Chocolate & Marshmellow & $\mathrm{R} \$ 20,57$ \\
Crocante & Chocolate & $\mathrm{R} \$ 31,95$ \\
Crocante & Marshmellow & $\mathrm{R} \$ 21,17$ \\
Mista & Chocolate & $\mathrm{R} \$ 29,28$ \\
Mista & Marshmellow & $\mathrm{R} \$ 20,44$ \\
Limão & Chocolate & $\mathrm{R} \$ 25,31$ \\
Limão & Marshmellow & $\mathrm{R} \$ 19,16$ \\
\hline
\end{tabular}

Nota. Fonte: Próprio autor.

Considerando o custo total para as tortas de tamanho 2, apresentado na Tabela 14 , tem-se $71 \%$ de matéria-prima, $13 \%$ de mão de obra e $8 \%$ de energia com relação ao custo total. O custo gerencial das tortas tamanho 3 são apresentados na Tabela 14.

Tabela 14

Custo gerencial de tortas tamanho 3

\begin{tabular}{lcc}
\hline Sabor & Cobertura & Custo Gerencial \\
\hline Maracujá & Chocolate & $\mathrm{R} \$ 32,31$ \\
Maracujá & Marshmellow & $\mathrm{R} \$ 27,70$ \\
Chocolate & Chocolate & $\mathrm{R} \$ 35,09$ \\
Chocolate & Marshmellow & $\mathrm{R} \$ 27,12$ \\
Crocante & Chocolate & $\mathrm{R} \$ 35,44$ \\
Crocante & Marshmellow & $\mathrm{R} \$ 25,45$ \\
Mista & Chocolate & $\mathrm{R} \$ 38,55$ \\
Mista & Marshmellow & $\mathrm{R} \$ 27,34$ \\
Limão & Chocolate & $\mathrm{R} \$ 32,86$ \\
Limão & Marshmellow & $\mathrm{R} \$ 26,07$ \\
\hline
\end{tabular}

Nota. Fonte: Próprio autor.

Os custos gerenciais das tortas tamanho 3 são divididos pela seguinte proporção: $70 \%$ de matéria-prima, $14 \%$ de mão de obra direta, $7 \%$ de energia e $9 \%$ representando os outros custos. 
Avaliação de Custos e Desperdícios na linha de Produção de Tortas Promocionais em uma Indústria de Alimentos

Carla Andréa Mendonça de Albuquerque, Maria Silene Alexandre Leite, Stela de Lourdes Ribeiro de Mendonça

Durante o processo de observação, identificou-se que os ingredientes não são pesados durante o processo de fabricação da massa do bolo, nem na finalização deste. $\mathrm{Na}$ confeitaria todos os ingredientes devem ser pesados, inclusive os líquidos para que haja padronização e evitar defeitos e desperdícios.

Dentre os custos encontrados nos três tamanhos de tortas, os mais significativos foram os diretos e o custo com energia. Para entender o comportamento e a motivação disso se realizou uma análise dos sete tipos de desperdícios realizados no processo de fabricação das tortas, posto que, são custos incorporados ao processo.

Para diminuir o custo com valor agregado dos processos é necessário diminuir as atividades que não agregam valor, por meio da identificação dos desperdícios, aumentando assim o lucro.

\subsection{Identificação dos desperdícios no processo de produção de tortas promocionais}

a) Análise conforme a agregação de valor

De acordo com Womack e Jones (2009), agregar valor é diferenciar o produto dos demais oferecidos no mercado que atenda às necessidades do cliente a um preço e momento específicos.

Para identificar os desperdícios no processo, inicialmente, os elementos anteriormente descritos pela cronoanálise, foram divididos em operações que agregam valor, ou seja, que poderão ser percebidas pelo consumidor do produto, atividades que não agregam valor, mas são necessárias para o processo e, por fim, atividades que não agregam valor. Para facilitar a identificação das atividades se utilizou o fluxograma apresentado na Figura 3. 


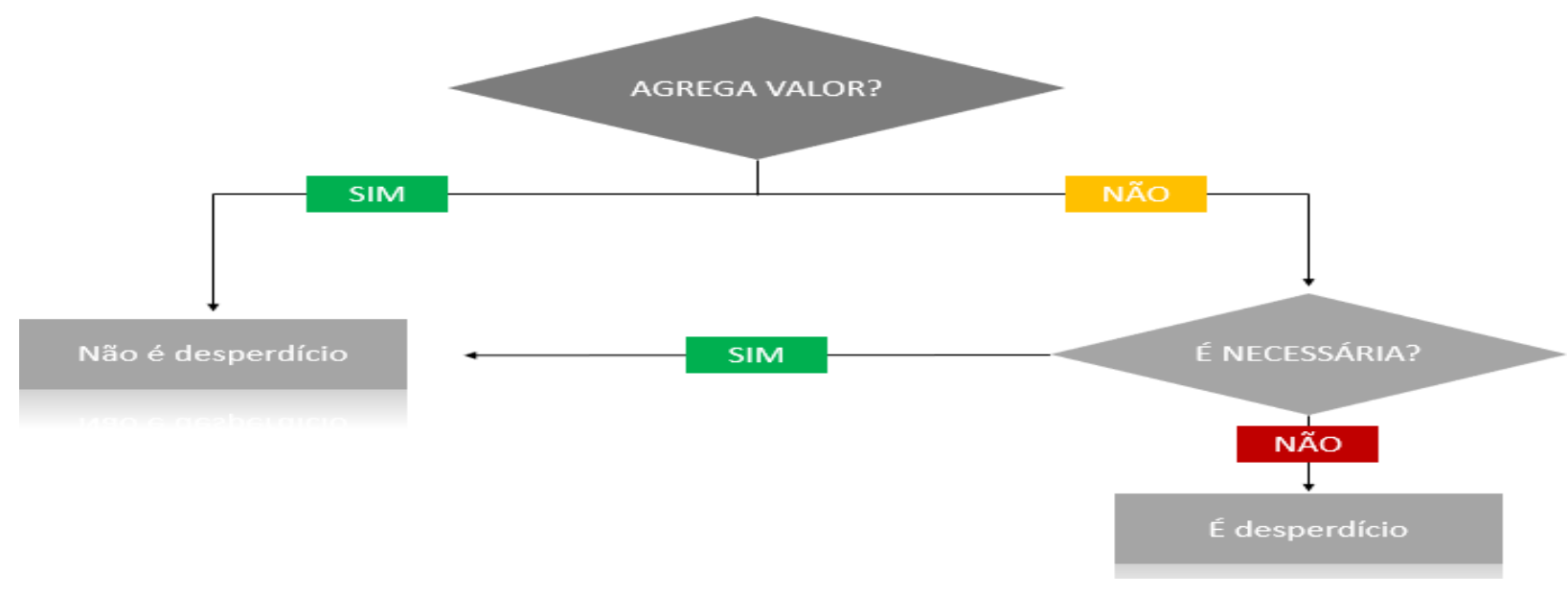

Figura 3. Análise da agregação de valor das atividades

Fonte: Próprio autor.

A tortas com sabor crocante apresentaram 15 atividades que agregam valor, 2 atividades que são necessárias para o processo, mas não agregam valor e 22 de desperdícios. As tortas de limão apresentam quantidades iguais de desperdícios e atividades que agregam valor, cada uma delas correspondem a 14 atividades, totalizando $48,3 \%$ para cada e apenas 1 atividade necessária. Os sabores de torta de chocolate, mista e maracujá possuem número de desperdícios superior ao de atividades que agregam valor e quantidade de atividades necessárias mínimos. Representando $56,4 \%, 55,8 \%$ e $56,4 \%$ respectivamente.

$\mathrm{Na}$ Tabela 15, tem-se os resultados obtidos através da análise de agregação de valor das atividades na produção dos cinco sabores de tortas. 
Avaliação de Custos e Desperdícios na linha de Produção de Tortas Promocionais em uma Indústria de Alimentos Carla Andréa Mendonça de Albuquerque, Maria Silene Alexandre Leite, Stela de Lourdes Ribeiro de Mendonça

Tabela 15

Identificação de atividades de acordo com a agregação de valor

\begin{tabular}{lccc}
\hline \multicolumn{1}{c}{ Produto } & Agrega Valor (\%) & Necessária (\%) & Desperdício (\%) \\
\hline Torta de Limão & 48,3 & $/ 3,4$ & 48,3 \\
Torta de Maracujá & 35,9 & 2,6 & 56,4 \\
Torta de Chocolate & 30,8 & 2,6 & 56,4 \\
Torta Mista & 42,3 & 1,9 & 55,8 \\
Torta Crocante & 38,5 & 5,1 & 56,4 \\
\hline Média & 39,1 & 3,1 & 54,7 \\
Desvio Padrão & 6,6 & 1,2 & 3,6 \\
\hline
\end{tabular}

Nota. Fonte: Próprio autor.

Somando todas atividades da linha de produção de tortas de acordo com sua agregação de valor, encontrou-se que $54,7 \%$ dessas atividades são consideradas como desperdícios para empresa em estudo. Como mostra a Figura 4.

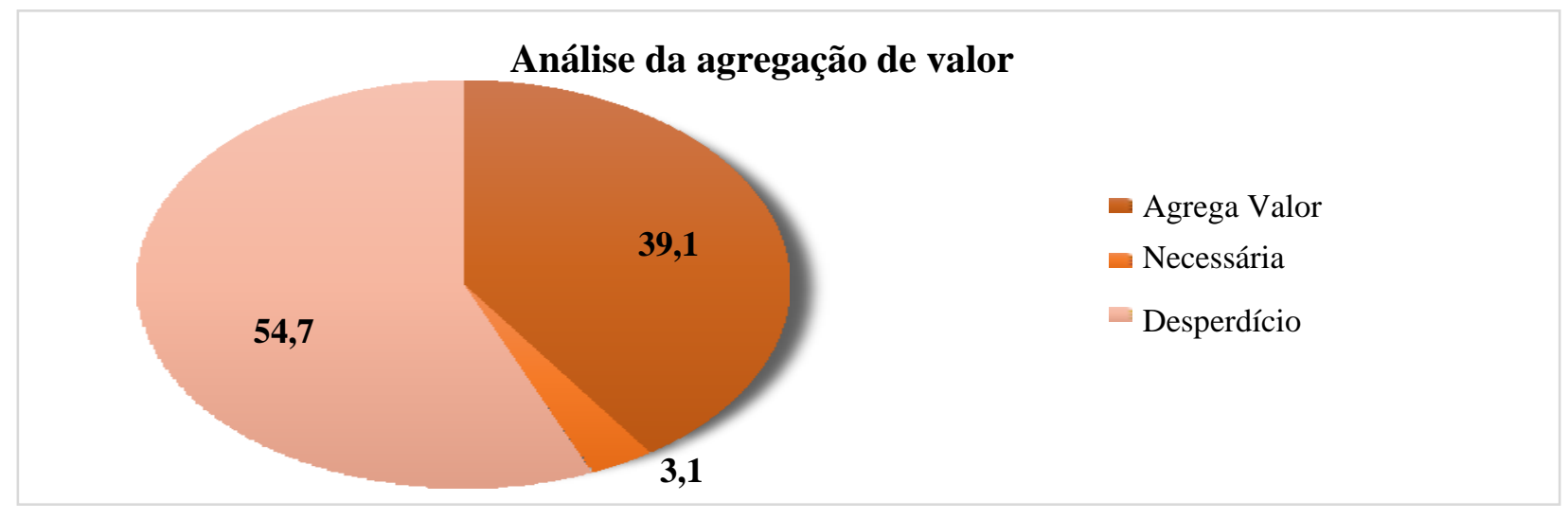

Figura 4. Gráfico de análise da agregação de valor das atividades

Fonte: Próprio autor.

Como mostra a Figura 4 há uma elevada quantidade de atividades que não agregam valor ao produto dentro processo, assim há uma grande oportunidade de reduzir os custos do produto através da eliminação dessas atividades identificadas que correspondem a $54,7 \%$ do total. 
Avaliação de Custos e Desperdícios na linha de Produção de Tortas Promocionais em uma Indústria de Alimentos

Carla Andréa Mendonça de Albuquerque, Maria Silene Alexandre Leite, Stela de Lourdes Ribeiro de Mendonça

\subsection{Classificação dos desperdícios}

A partir da análise de agregação de valor foi possível identificar quais atividades são consideradas desperdícios e então classificá-los entre os sete tipos de atividades que não agregam valor, de acordo com os resultados na Tabela 16.

Tabela 16

Classificação dos desperdícios por sabor de torta

\begin{tabular}{lccccccc}
\hline Desperdício & $\begin{array}{c}\text { Torta de } \\
\text { Limão }\end{array}$ & $\begin{array}{c}\text { Torta de } \\
\text { Maracujá }\end{array}$ & $\begin{array}{c}\text { Torta de } \\
\text { Chocolate }\end{array}$ & $\begin{array}{c}\text { Torta } \\
\text { Mista }\end{array}$ & $\begin{array}{c}\text { Torta } \\
\text { Crocante }\end{array}$ & Média & $\begin{array}{c}\text { Desvio } \\
\text { Padrão }\end{array}$ \\
\hline ESPERA & $28,6 \%$ & $18,2 \%$ & $18,2 \%$ & $20,7 \%$ & $18,2 \%$ & $20,8 \%$ & 4,50 \\
MOVIMENTAÇÃO & $21,4 \%$ & $13,6 \%$ & $13,6 \%$ & $10,3 \%$ & $13,6 \%$ & $14,5 \%$ & 4,11 \\
SUPERPRODUÇÃO & $14,3 \%$ & $9,1 \%$ & $9,1 \%$ & $12,1 \%$ & $9,1 \%$ & $10,7 \%$ & 2,37 \\
PRODUTOS & $0,0 \%$ & $36,4 \%$ & $36,4 \%$ & $27,6 \%$ & $36,4 \%$ & $27,3 \%$ & 15,75 \\
DEFEITUOSOS & & & & & & & \\
PROCESSAMENTO & $7,1 \%$ & $4,5 \%$ & $4,5 \%$ & $10,3 \%$ & $4,5 \%$ & $6,2 \%$ & 2,56 \\
ESTOQUE & $14,3 \%$ & $9,1 \%$ & $9,1 \%$ & $12,1 \%$ & $9,1 \%$ & $10,7 \%$ & 2,37 \\
TRANSPORTE & $14,3 \%$ & $9,1 \%$ & $9,1 \%$ & $6,9 \%$ & $9,1 \%$ & $9,7 \%$ & 2,74 \\
\hline
\end{tabular}

Nota. Fonte: Próprio autor.

Através da Figura 5 é possível visualizar os tipos de desperdícios mais presentes nas atividades da linha de produção de tortas promocionais.

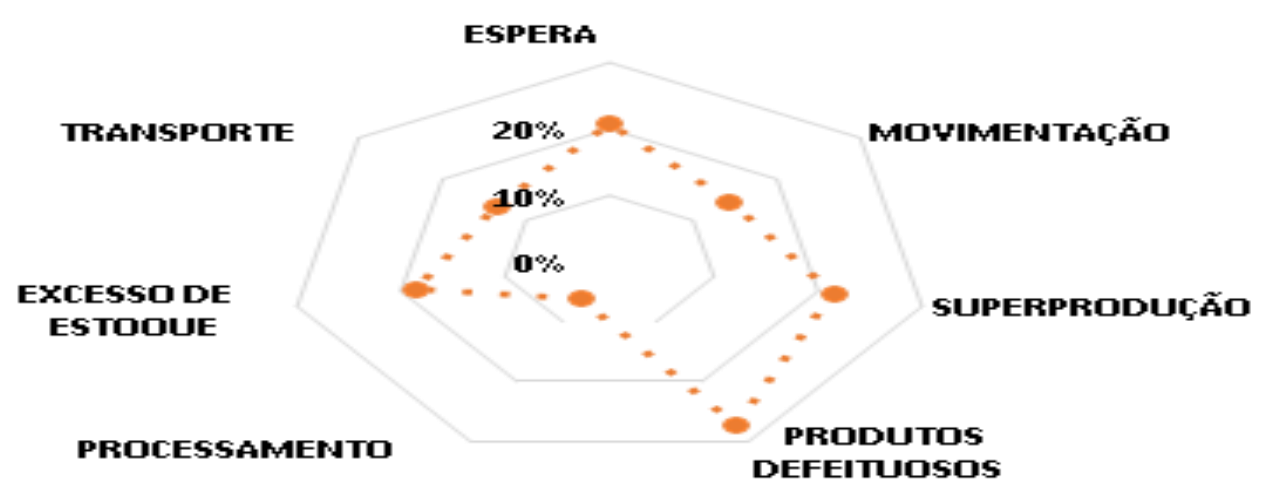

Figura 5. Desperdícios na linha de produção de tortas

Fonte: Próprio autor. 
Avaliação de Custos e Desperdícios na linha de Produção de Tortas Promocionais em uma Indústria de Alimentos

Carla Andréa Mendonça de Albuquerque, Maria Silene Alexandre Leite, Stela de Lourdes Ribeiro de Mendonça

Desperdícios por espera na linha de produção de tortas ocorrem principalmente quando o produto já finalizado aguarda a demanda de pedidos ou quando ainda está em processo e necessita aguardar a próxima operação. Nesse contexto, a torta de limão é a que obteve maior percentual $(28,6 \%)$, posto que a demanda por esse sabor de torta é inferior aos dos outros sabores analisados. Para que esse seja reduzido é necessário que haja um balanceamento das quantidades produzidas e capacidades de produção de cada setor ou etapa de processo.

O excesso de produção da empresa é um desperdício que causa outro, que é o de estoque e está presente em $10,7 \%$ das atividades da linha de produção de tortas. Esse desperdício ocorre principalmente devido à ausência de implantação de um sistema de PCP. Apesar de muitas empresas entenderem que excesso de produto em estoque é um ativo de valor, esses produtos estão gerando um custo adicional para serem mantidos até ocorrer a venda, como manutenção e ocupação da área. As ações que podem ser realizadas para evitá-los são melhorar o processo de estocagem, nivelando as quantidades e sincronizando os processos; melhoria do layout da fábrica; melhoria na operação, redução de tempos de preparo e ajustes de máquinas.

Operações como separar materiais são consideradas como desperdícios de movimento que se trata da produção e/ou armazenamento de produtos acabados, em processo ou matéria-prima acima das necessidades de segurança da empresa. Esse desperdício gera um custo desnecessário de mão de obra, já que o operador precisa se deslocar do seu posto de trabalho e separar seu material várias vezes por dia, de acordo com a necessidade. Propõe-se que todo o material que o operador irá precisar durante o dia esteja próximo ao local de realização do processo e que haja uma boa organização de trabalho.

A linha de produção em estudo não apresenta um fluxo de operações de forma contínua, desse modo, esses contribuem para o aumento das movimentações entre os postos de trabalho, caracterizado como desperdício por transporte, gerando um custo de mão de obra. Para eliminar desperdícios por transporte é necessário ter todos os 
Avaliação de Custos e Desperdícios na linha de Produção de Tortas Promocionais em uma Indústria de Alimentos

Carla Andréa Mendonça de Albuquerque, Maria Silene Alexandre Leite, Stela de Lourdes Ribeiro de Mendonça

componentes próximos, executar operações de melhoria do layout da empresa, assim como a mecanização e/ou automação dos processos.

Devido a ausência de controle de estoque na empresa, faz-se necessário realizar a contagem de produtos em estoque, essa atividade é considerada como desperdício por processamento, pois poderia ser eliminada sem ônus as características do produto e afeta diretamente a produtividade e o custo da operação.

O desperdício da massa de bolo em processo, acontece pela produção de produtos defeituosos que possuem grande representatividade dentre os desperdícios da linha de produção de tortas. Sendo que esses acarretam a perda de material, mão de obra e tempo de máquina, além disso, sua correção gera mais custos em função do reprocesso.

Com base na análise do processo, propõe-se principalmente que a metodologia de operação seja reavaliada. Por meio da maioria dos desperdícios, presentes na linha de produção de tortas promocionais, estão relacionados com a falta de balanceamento de linha, padronização do processo e ausência de sistema de planejamento e controle da produção. Diante disso, faz-se necessário a padronização de processos que, conforme pontuado na revisão de Santos (2018), pode contribuir com a redução de falhas, maior rendimento da gestão de projetos e eficiência na organização.

\section{CONSIDERAÇÕES FINAIS}

Seguindo as recomendações do sistema de produção enxuta, percebeu-se que os custos de produção da empresa, com a linha de tortas promocionais são altos, devido aos elevados tempos de armazenamento, dos custos com matérias-primas e com a mão de obra direta. Para que possam diminuir esses custos é necessário reduzir a grande quantidade de atividades consideradas como desperdícios. Posto que $54,7 \%$ dessas atividades contribuem para o alto índice de desperdícios.

Nesse sentido, este estudo teve como contribuição teórica a associação da gestão de custos com análise de desperdícios, mostrando percentuais de custos 
Avaliação de Custos e Desperdícios na linha de Produção de Tortas Promocionais em uma Indústria de Alimentos

Carla Andréa Mendonça de Albuquerque, Maria Silene Alexandre Leite, Stela de Lourdes Ribeiro de Mendonça

oriundos de desperdícios gerados e possíveis de eliminação. Ainda, como contribuição prática, a organização de planilhas eletrônicas para gestão dos custos de produção da empresa estudada, oferecendo a possibilidade de melhor organização dos tipos de gastos e consequentemente uma melhor gestão.

A abordagem do Lean Manufacturing, para apuração dos desperdícios também foi empregada, bem como a utilização das ferramentas de cronoanálise e diagrama de fluxo do processo.

Levando em consideração a competitividade do mercado atual, a implantação do sistema de produção enxuta na empresa pode contribuir de forma significativa para a redução de custos em suas linhas de produção, colocando-a em um patamar mais elevado em relação a concorrência local.

\section{REFERÊNCIAS}

ABIP. (2018). Associação Brasileira de Panificação e Confeitaria. Análise do mercado de panificação e confeitaria.

ABNT NBR. (2000). ISO 9001: sistemas de gestão da qualidade: requisitos. Rio de Janeiro.

Albertin, M., \& Guertzenstein, V. (2018). Planejamento Avançado da Qualidade. Rio de Janeiro.

Antunes, J. (2008). Sistema de Produção: conceitos e práticas para projeto e gestão da produção enxuta. Porto Alegre: Bookman.

Azevedo, B. M. M. (2011). Modelo de Implementação de Sistema de Produção Lean no INESC Porto. (Dissertação de Mestrado). Faculdade de Engenharia da Universidade do Porto, FEUP, Portugal.

Barnes, R. M. (1982). Estudo de Movimentos e de Tempos: Projeto e Medida do Trabalho. São Paulo. Edgard Blucher. (6a ed.).

Bornia, A. C. (2010). Análise Gerencial de Custos: Aplicação em empresas modernas. (3a ed.). 
Avaliação de Custos e Desperdícios na linha de Produção de Tortas Promocionais em uma Indústria de Alimentos

Carla Andréa Mendonça de Albuquerque, Maria Silene Alexandre Leite, Stela de Lourdes Ribeiro de Mendonça

Chiavenato, I. (1993). Introdução à teoria geral da administração. (4a ed.). São Paulo: Makron Books.

Costa, N. A. da. (2017). Eliminação de desperdícios e aumento de produtividade na indústria: enfrentando a crise com base no STP. (Monografia). Especialização em Engenharia de Produção. Universidade Tecnológica Federal do Paraná. Ponta Grossa, Brasil.

Demeneck, R. C. (2014). Aplicação do método de custeio variável - estudo de caso em uma indústria do setor de panificação e confeitaria cooperada junto a Coofanove do Município de Nova Veneza/SC. (Trabalho de Conclusão de curso). Universidade do Extremo Sul Catarinense, UNESC, Santa Catarina, Brasil.

Fernandes, L. J. M., \& Freitas, L. S. (2014). Análise do processo produtivo de uma panificadora na cidade de Campina Grande-Paraíba utilizando a ferramenta de P+ L. Revista Espacios, Vol. 35 (№ 5).

Geitenes, S. (2013). Princípios da produção enxuta: um estudo de caso para avaliação dos desperdícios no processo produtivo e melhorias no layout em uma indústria de vidros. (Trabalho de Conclusão de Curso). Universidade Tecnológica Federal do Paraná, Brasil.

Lacerda, M. S. P., Walter, F., \& Schultz, C. A. (2011). A aplicação do método UEP em uma panificadora: medidas de custo e de desempenho. Congresso Brasileiro de Custos, Rio de Janeiro, RJ, Brasil, 18.

Leone, G. S. G. (2000). Custos -Planejamento, implantação e controle. (3a ed.).

Liker, J. K., \& Meier, D. (2007). O modelo toyota-manual de aplicação: um guia prático para a implementação dos $4 P s$ da toyota. Bookman Editora.

Magro, C. B. D, Manfroi, L., Bortoli, L. A., \& Theisen, C. P. (2014). A contabilidade de custos na formação do preço de venda: um estudo de caso na indústria de panificação. Congresso Brasileiro de Custos, Natal, RN, Brasil, 21.

Milani, I. L. et al. (2016). Ferramentas da qualidade na identificação dos desperdícios e suas causas: Estudo de caso numa microempresa do setor alimentício. Contribuições da Engenharia de Produção para Melhores Práticas de Gestão e Modernização do Brasil João Pessoa/PB, Brasil.

Nascimento, E. L. et al. (2012). Modelagem de informações no desenvolvimento enxuto de projetos. 
Avaliação de Custos e Desperdícios na linha de Produção de Tortas Promocionais em uma Indústria de Alimentos Carla Andréa Mendonça de Albuquerque, Maria Silene Alexandre Leite, Stela de Lourdes Ribeiro de

Oliveira, L. P. (2016). Análise dos sete desperdícios da produção em um abatedouro de aves. (Projeto de Graduação). Universidade de Brasília, UnB, Brasil.

Ohno, T. (1997). O sistema Toyota de produção além da produção. Bookman Editora.

Peinado, J., \& Graeml, R. A. (2007). Administração da produção. (1a ed.). Curitiba: Unicenp.

Rezende, D. M. et al. (2013). Lean Manufacturing: Redução de desperdícios e a padronização do processo.

Shingo, S. (1996). Sistema toyota de produção: do ponto-de-vista de engenharia de produção. Porto Alegre: Bookmann

Slack, N., Chambers, S., \& Johnston, R. (2009). Administração da Produção. (3a ed.). São Paulo: Editora Atlas S.A.

Sugai, M. (2003). A Avaliação do Impacto do MTM em uma Empresa Metal-Mecânica. Faculdade de Engenharia Mecânica, Universidade Estadual de Campinas.

Data de Submissão: 16/12/2019

Data de Aceite: 10/08/2020 